\title{
BACKGROUND
}

Students do not expect to write and are typically reluctant to write in a math course.

Explain that writing is a tool to understanding and will be emphasized in this course. Simple mathematics are used to solve complicated problems and understanding the problem situation, the data and concepts are important to understand prior to applying even simple mathematics.

Communicating the meaning of data is important in quantitative analysis. Clear communication is key to demonstrating a good understanding of the task. Practicing communication will result in excellent problem-solving skills.

\section{COURSE COMPETENCIES}

1) Utilize mathematical and algebraic laws to perform mathematical operations.

- You understand how the proper use of a calculator.

- You solve expressions using the order of operations, commutative laws, distributive laws, associative laws, exponent laws, scientific notation, and engineering notation.

\section{UNDERSTANDING THE TASK}

Encourage students to ask the following questions.

- What is the topic of the task?

- What is the task telling me to do?

- How can I find the answer?

- What data is required to complete the task?

- What is a reasonable prediction of the answer? (builds self-confidence)

- Why do I think I have the right answer?

Writing Principle:

Throughout the course, but especially in Learning Module 1, watch for opportunities to encourage students to develop their writing skills. I have them verbalize the process instead of just applying formulas.

Here are some strategies you can use:

- Model correct terminology use and complete statements by restating student responses in class.

- When you are talking about a question in class that is like a writing prompt, write a oneto three-sentence answer.

- Example: Given current and resistance, determine the voltage. The voltage is mathematically determined by multiplying the current by the resistance. Therefore, the voltage (in volts) is the product of the current (in amps) and the resistance (in ohms).

\section{EXPLICIT CONNECTIONS}

It is important that each person feels equally important in the classroom. The very first day is important in creating a classroom environment in which everyone feels comfortable enough to ask questions, assist colleagues and participate in discussions. Closely observe students especially during the icebreaker.

Start building good trouble shooting strategies the first day of class. 


\section{NOTES TO SELF}

- Divide into groups the first day but as you get to know the class, groups can change.

- I would require each student to open Blackboard and complete the three pre-class assessments. These pre-class assessments should be open and available when you sent the welcome email that encourages the students to prepare for the course. These will give you good feedback as to the abilities of the students, forces everyone to work in Blackboard, and models it as a teaching/learning resource.

- It is difficult for the students to first critically think about questions that are asked of them and then to guess at an answer. Predictions are important to building confidence and they should know that there must be a certain expectation of failure - nobody is correct all of the time - but without some starting point, it will be impossible to come to any conclusion at all.

Note: The Blackboard: Practice Set lessons are repetitive work for students to build confidence in the subject matter. They are topic specific, straightforward calculation questions that test students in the knowledge of the topic. As such, they are not 'contextualized' but form the supporting teaching material.

\begin{tabular}{|c|l|l|}
\hline $\begin{array}{c}\text { Duration } \\
\text { Minutes }\end{array}$ & \multicolumn{1}{|c|}{ Lesson } & Suggested Structure \\
\hline 20 & Introduction and ice Breaker & Cohort \\
\hline 40 & Introduction to course & Cohort \\
\hline 20 & Lecture: Basic arithmetic skills & Cohort \\
\hline 15 & Blackboard: Practice Set 1 - Basics & Individual \\
\hline 15 & Problem Set 1.1: Introduction to Quantitative Reasoning & Group \\
\hline 20 & Lecture: Percentages and Dimensional Analysis & Cohort \\
\hline 45 & Problem Set 1.2: Dimensional Analysis & Group \\
\hline 20 & Lecture: Engineering Notation & Cohort \\
\hline 30 & Problem Set 1.3: Engineering Notation & Cohort \\
\hline 20 & Fractions and Ratios Lecture & Cohort \\
\hline 25 & Problem Set1.4 Transformers & Group \\
\hline 30 & Quiz & Cohort \\
\hline
\end{tabular}




\begin{tabular}{|c|l|l|}
\hline Lesson & Objectives & Material \\
\hline \hline Intro & Introduction to course & Course documents \\
\hline 1.0 & Review of basic arithmetic skills & Lecture \\
\hline 1.1 & Introduction to Quantitative Reasoning & $\begin{array}{l}\text { Introduction to Quantitative } \\
\text { Reasoning }\end{array}$ \\
\hline 1.2 & Dimensional Analysis & Cost of Power \\
\hline 1.3 & Scientific notation \& Engineering Notation & Engineering Notation \\
\hline 1.4 & Fractions and Ratios & Transformers \\
\hline
\end{tabular}

\section{Prerequisite Assumptions}

Before beginning the lesson, students should be able to;

- Multiply two fractions

- Divide two fractions

- Simplify fractions by 'canceling' or dividing common factors in the numerator and denominator

- Multiply fractions by 1 to create a common denominator.

The following is Adapted from @ 2014 THE CARNEGIE FOUNDATION FOR THE ADVANCEMENT OF TEACHING

Quantitative reasoning: You might be surprised that you are asked to write short responses to questions. This course emphasizes writing for the following two reasons:

- Writing is a learning tool. Explaining things such as the meaning of data, how you calculated the data, or how you know your answer is correct deepens your own understanding of the material.

- Writing is a means of communication. Products in today's world, such as reports, news articles, publicity materials, advertising, and grant applications, contain quantitative information. Being able to communicate quantitatively is an important literary skill.

Understanding the task: One important strategy is to make sure you understand the task. In this course, your tasks will be answering questions in the assignments, but in other life situations the task might be answering a question on a report form, following instructions from your employer, or working towards a goal that you set for yourself. To begin to write successfully, ask yourself the following questions:

- What is the question / task?

- What is the task telling me to do? Some examples are given below:

$\checkmark$ Reflect and describe on the process of coming up with the answer.

$\checkmark$ Make a prediction

$\checkmark$ Compare two data points or the answers to two parts of the problem

- What information do I have to help me with the task?

- What is the likely relationship between my task and the information I have?

Does the information make sense? During this course, you will be presented with a number of problem situations. These problem situations will help you learn how to evaluate the types of quantitative information you may encounter in everyday life.

For example, math is used every time you decide which cable package to sign up for, when you get a medical bill, and when you look at interest on your credit cards. Marketers use math sometimes to make a product seem better or more widely used than it actually is - how can you make good decisions and save money if you can't tell when they're being sneaky? Math 
also gets used in politics all the time. On TV they report surveys that, for instance, say $80 \%$ of people approve of something - but $80 \%$ of which people? These types of everyday math problems don't require complicated math - it's mostly addition, subtraction, division, etc. But they do require complex thinking. This course is about the use of straightforward math to do complex thinking

When presented with a problem situation you should;

- Write down the question / task.

$\checkmark \quad$ Reflect and write the process of coming up with the answer. You may also make a prediction at this point to develop an insight into the problem.

- Write down the information you are given.

- Solve the problem.

\section{Specific Objectives}

By the end of this lesson, you should understand;

$\checkmark$ Quantitative reasoning is the ability to understand and use quantitative information. It is a powerful tool in making sense of the world.

$\checkmark$ Relatively simple math can help make sense of complex situations.

$\checkmark 1,000,000,000,10^{9}$, and $1 \mathrm{G}$ have the same meaning

$\checkmark$ Engineering notation

By the end of this lesson, you should be able to;

$\checkmark$ identify quantitative information

$\checkmark$ convert engineering notation to and from different notations (e.g. ordinary and scientific notation)

$\checkmark$ understand how to work with fractions and ratios

$\checkmark$ understand how to calculate percentage increases and decreases

$\checkmark$ work in groups and participate in meaningful discussions

$\checkmark$ understand how to properly use a calculator

$\checkmark$ solve expressions using the order of operations, commutative laws, distributive laws, associative laws, exponent laws, scientific notation, and engineering notation

\section{Problem Situation 1.1 - Introduction to Quantitative Reasoning ${ }^{1}$}

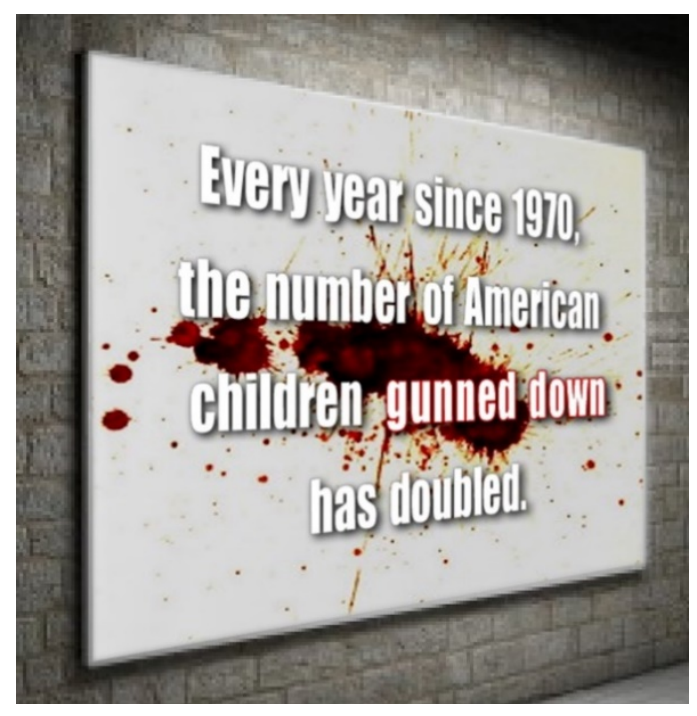

Imagine that you just received a flier in the mail with the following statement: ${ }^{2}$

1) What are some social issues or political ideas that this statement might support?

2) Do you think the statement "Every year since 1970, the number of children gunned down has doubled," is a reasonable statement? Discuss with your group. 
The flier in "Problem Situation 1.1" includes quantitative information. Quantitative information uses concepts about quantity or number (this can be specific numbers, or a pattern based on numerical relationships such as doubling).

You hear and see statements that include quantitative information every day. People use these statements as evidence to convince you to do things like

- vote a certain way;

- donate or give money to a cause; or

- understand a health risk.

You often do not know whether these statements are true. You may not be able to locate the information that supports these statements, but you can start by asking if the statements are reasonable. This means asking if the statements make sense.

Using only the information that was included in the flier, how can you decide if the statement was reasonable? Talk with your group about the different ways in which you might answer this question.

3) In the previous question, you thought about how to decide if the statement was reasonable. One approach is to start with a number for the first year.

a. Start with " 1 " and fill in the following table.

b. Complete the other values in the second column of the table.

c. Round the number to three significant digits in the third column.

\begin{tabular}{|l|l|l|}
\hline \multicolumn{1}{|c|}{ Year } & Number of children gunned down & Rounded to 3 significant digits \\
\hline $\mathbf{1 9 7 0}$ & $\mathbf{1}$ & 1 \\
\hline $\mathbf{1 9 7 5}$ & 32 & 32 \\
\hline $\mathbf{1 9 8 0}$ & 1,024 & 1,020 \\
\hline $\mathbf{1 9 8 5}$ & 32,768 & 32,800 \\
\hline $\mathbf{1 9 9 0}$ & $1,048,576$ & $1,050,000$ \\
\hline $\mathbf{2 0 0 0}$ & $1,073,741,824$ & $1,070,000,000$ \\
\hline $\mathbf{2 0 1 0}$ & $1,099,511,627,776$ & $1,100,000,000,000$ \\
\hline $\mathbf{2 0 1 7}$ & $140,737,488,355,328$ & $141,000,000,000,000$ \\
\hline
\end{tabular}

4) Refer to the table you created in the previous question. Does the number of children gunned down in the year 2017 seem reasonable?

${ }^{1}$ Adapted from @ 2014 THE CARNEGIE FOUNDATION FOR THE ADVANCEMENT OF TEACHING

${ }^{2}$ Adapted from Joel Best, Damned Lies and Statistics: Untangling Numbers from the Media, Politicians, and Activists (Berkeley: University of California Press, 2001). 


\section{Problem Situation 1.2 - Cost of power - Dimensional analysis, percentages, units}

A watt, named after James Watt, is a unit of power and is defined as the rate of energy transfer. An electronic device, such as a refrigerator, microwave, motor or hair dryer converts electrical energy into mechanical energy or heat. The watt is the rate energy is used. A watt is one joule per one second, the symbol J/s. A kilo Watt $(\mathrm{kW})$ is 1000 Watts. Your electric bill is based on the power consumed in kilo Watt hours $(\mathrm{kWh}) .1 \mathrm{kWh}=1000$ Watts consumed in 1 hour $=500$ Watts consumed in 2 hours

Madison Gas and Electric (MGE) has a seasonal rate structure with summer rates charged from June 1 through September 30 and the winter rate applies the remainder of the year.

\begin{tabular}{|c|c|}
\hline \multicolumn{2}{|c|}{ Per kWh Rate } \\
\hline Summer $-6 / 1-9 / 30$ (122 days) & Winter - 10/1-5/31(243 days) \\
\hline$\$ 0.141630$ & $\$ 0.130250$ \\
\hline
\end{tabular}
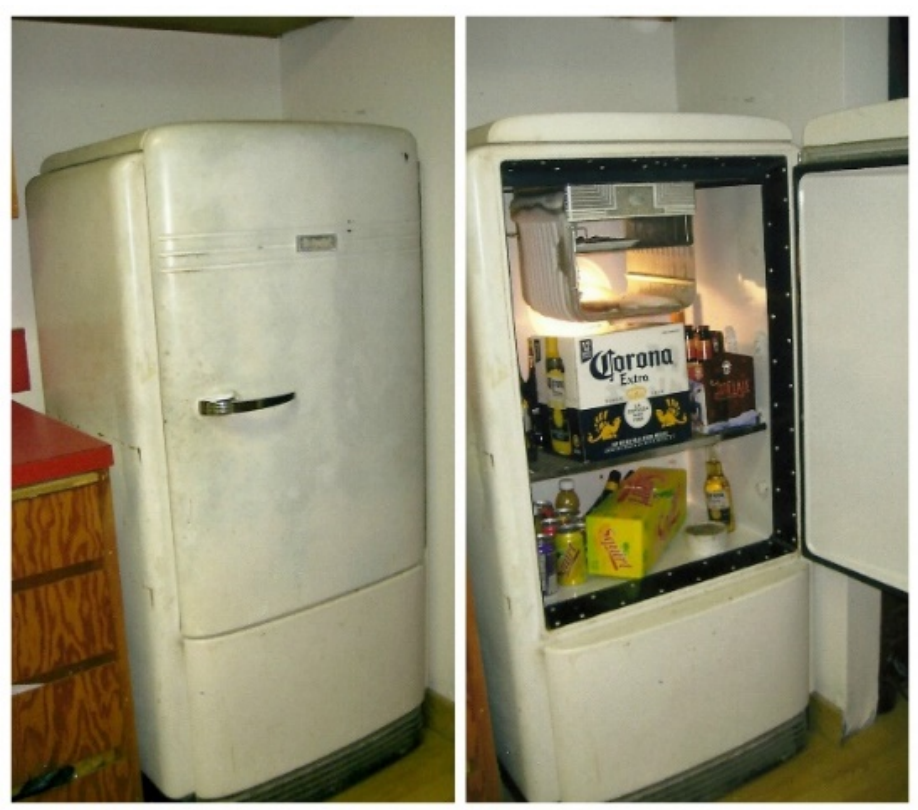

1) This old refrigerator still runs and keeps the contents mostly cold. How much to you think this fine appliance would cost to operate annually for an average family?

Most of the students don't want to guess because they have no experience. It may be an opportunity for some students to learn how to conduct an internet search quickly.

2) What information would you need to determine the actual impact of this appliance on the electric bill?

How much does energy cost? Given above

How much energy is used? How long does the refrigerator run?

The 800 -Watt compressor runs about $43 \%$ of the 24 -hour day. 
3) How many hours a day does the compressor run? I need to determine the actual run time of the refrigerator. The time is given to me as a percentage of the whole day.

$43 \%$ of 24 hours $=0.43 * 24$ hours $=10.32$ hours $\sim 10.3$ hrs ( 3 significant digits)

4) How many kWh are consumed daily?

I need to determine the $\mathrm{kWh} . \mathrm{K}=1000, \mathrm{~W}=800$ Watts, $\mathrm{h}=10.32$ hours

$$
\frac{1 \mathrm{~kW}}{1000 W} * \frac{800 W}{1} * \frac{10.32 h}{1}=8.256 \mathrm{kWh} \sim 8.26 \mathrm{kWh}
$$

5) What is the cost to operate this refrigerator in the summer?

I need to determine the cost of operation for the summer months, which is 122 days. The refrigerator uses $8.256 \mathrm{kWh}$ each day and we pay $\$ 0.14163$ for each $\mathrm{kWh}$.

$$
\frac{8.256 \mathrm{kWh}}{\text { day }} * \frac{122 \text { days }}{\text { Summer }} * \frac{\$ 0.14163}{\mathrm{kWh}}=\$ 142.64 \sim \$ 143 \text { per summer }
$$

6) What is the cost to operate this refrigerator in the winter?

I need to determine the cost of operation for the winter months, which is 249 days. The refrigerator uses $8.256 \mathrm{kWh}$ each day and we pay $\$ 0.13025$ for each $\mathrm{kWh}$.

$$
\frac{8.256 \mathrm{kWh}}{\text { day }} * \frac{249 \text { days }}{\text { Winter }} * \frac{\$ 0.13025}{\mathrm{kWh}}=\$ 261.31 \sim \$ 261 \text { per winter }
$$

7) What is the total annual cost of operation?

I need to determine the annual cost, so I need to add the summer and winter costs.

$\$ 142.64+\$ 261.31=\$ 403.96 \sim \$ 404$ annually

8) Would you recommend replacing this refrigerator? What criteria would you use to make the recommendation?

The students should discuss the method used to validate their conclusions. Good decisions are based on good data.

9) One sound method for this type of decision-making is the rate of return, gain or loss on an investment. Discuss with your group how you would determine the rate of annual savings. What information do you need? 

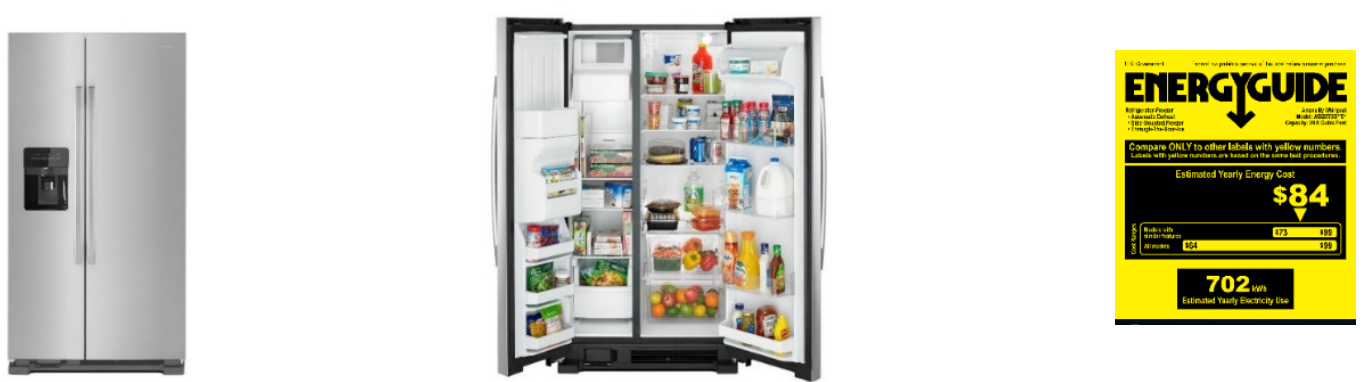

10) This Amana $24.6 \mathrm{cu}$. ft. Side by Side Refrigerator with Dual Pad External Ice and Water Dispenser in Stainless Steel has gotten good reviews, and it fits the same space. It is on sale for $\$ 897.30$, not including $5.6 \%$ sales tax. With purchase, there is an additional $\$ 20$ delivery charge, but disposal of the old unit is included. What is the total cost of the purchase?

I need the total cost of purchasing this refrigerator. This includes, purchase price, sales tax and delivery cost. Guess is the total cost $=\mathrm{xxx}$.

$\$ 897.30+(\$ 897.30 * 0.056)+\$ 20=\$ 967.55$

11) Assuming the energy rating is accurate; determine the annual savings, the annual percent savings and the amount of time to recover all of the investment.

I need to determine the annual savings, then the percent saved and the amount of time to recover the cost of the new refrigerator. Guess is xxx years.

Total Savings $=$ cost to operate the old refrigerator minus the cost to operate the new refrigerator $=\$ 404-\$ 84=\$ 320$

$\%$ saved annually $=\frac{\mid \text { initial value }- \text { new value } \mid}{\text { initial value }} * 100 \%=\frac{\$ 320}{\$ 404} * 100 \%=79.2 \%$

Full recovery $=\frac{\text { total cost of the new refigerator }}{\text { annual savings }}=\frac{\$ 967.55}{\$ 320}=3.02$ years

12) Would you now recommend replacement of the old refrigerator?

13) Now that you know how to make data driven decisions for appliances, you are thinking of upgrading your old 20-Watt TV. You want to purchase a 50" plasma TV that consumes about 300 Watts of energy. Your family loves to watch movies together especially in the cold winter months so the TV is typically on about 4 hours a day. What is the actual cost of operating each TV at $\$ 0.130250 / \mathrm{kWh}$ ? What is the percentage increase in energy consumption for the new 50" plasma TV over a 30-day month?

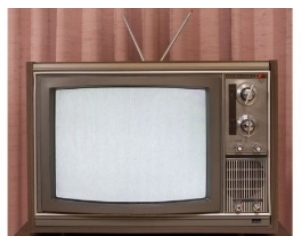

I need to determine the costs of operating both TVs. Guess is xxx.

Old: $\frac{30 \text { days }}{1 \text { month }} * \frac{4 \text { hrs }}{\text { day }} * \frac{20 \text { Watts }}{1} * \frac{1 \mathrm{kWatt}}{1000 \text { Watts }} * \frac{\$ 0.130250}{\mathrm{kWh}}=\$ 0.3126 / \mathrm{month}$

New: $\frac{30 \text {-days }}{1 \text { month }} * \frac{4 \text { hrs }}{\text { day }} * \frac{300 \text { Watts }}{1} * \frac{1 \mathrm{kWatt}}{1000 \text { Watts }} * \frac{\$ 0.130250}{\mathrm{kWh}}=\$ 4.689 / \mathrm{month}$

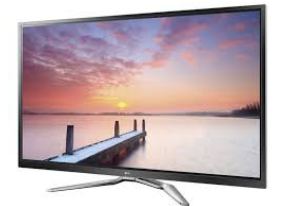

$\%$ change $=\frac{\mid \text { Initial value }- \text { new value } \mid}{\text { Initial value }} * 100 \%=\frac{|\$ 0.3126-\$ 4.689|}{\$ 0.3126} * 100 \%=1400 \%$ increase 


\section{Problem Situation 1.3 Talking Engineering - Engineering notation}

Engineering notation is used quite a bit, especially in the electronic industry. It is a form of writing and talking about really big and really small numbers easily. It is a version of scientific notation in which the exponent of ten must be divisible by three and the number left of the decimal point must be between 1 and 999 inclusive. Additionally, we also use a metric prefix name and corresponding symbol, to abbreviate the number even further.

\begin{tabular}{|c|c|c|r|}
\hline Name & Symbol & Multiplier & \multicolumn{1}{c|}{ Value } \\
\hline tera & $\mathrm{T}$ & $10^{12}$ & $1,000,000,000,000$ \\
\hline giga & $\mathrm{G}$ & $10^{9}$ & $1,000,000,000$ \\
\hline mega & $\mathrm{M}$ & $10^{6}$ & $1,000,000$ \\
\hline kilo & $\mathrm{k}$ & $10^{3}$ & 1,000 \\
\hline & & $10^{0}$ & 1 \\
\hline milli & $\mathrm{m}$ & $10^{-3}$ & 0.001 \\
\hline micro & $\mathrm{\mu}$ & $10^{-6}$ & 0.000001 \\
\hline nano & $\mathrm{n}$ & $10^{-9}$ & 0.000000001 \\
\hline pico & $\mathrm{p}$ & $10^{-12}$ & 0.000000000001 \\
\hline
\end{tabular}

1) We are surrounded by digital information from digital pictures, files, music, movies, etc. These bits of data are stored in hard drives, servers and in the cloud all across the world. Digital information is stored in bits and each bit is either a zero or a one. A bit, which is the smallest unit of storage, contains information that is defined by two separate states: one or zero, often considered on or off. EXAMPLE: A car door is closed / open $\leftrightarrow 1 / 0$.

There are 8 bits in a group called a byte. A letter in a text message requires a byte of storage space. If your message is 19 characters, it takes 19 bytes to store.

In 1975 a 5.25" floppy disk had a whopping capacity of 110 kilobytes. WOW! By the mid 1980's a single compact disc, CD, could hold 550 megabytes. In 2009 the first terabyte hard drive was introduced.

Given the following digital information, determine the number of bits and bytes.

\begin{tabular}{|l|l|l|}
\hline Device & \# bytes & \# bits \\
\hline 110 kilobyte (KB) disk & 110,000 & 880,000 \\
\hline 324-character text message & 324 & 2,592 \\
\hline 2.5 Terabyte (TB) hard drive & $2,500,000,000,000$ & $20,000,000,000,000$ \\
\hline 4 Gigabyte (GB) memory & $4,000,000,000$ & $32,000,000,000$ \\
\hline
\end{tabular}

2) There are 2 values that can be represented with 1 bit; it can either be 0 or 1 . The number of values represented doubles for every additional bit. 2 bits can be $\{00,01,10,11\}$ thus there are 4 potential configurations for 2 bits. Mathematically: $n$ bits $=2^{n}$ potential values. Determine the missing information in the table below for the number of potential configurations. 


\begin{tabular}{|c|c|c|c|c|c|c|c|c|c|c|}
\hline Bits & $2^{n}$ & & \multicolumn{8}{|c|}{ Potential configurations } \\
\hline 1 bit & $2^{1}$ & 2 & 0 & 1 & & & & & & \\
\hline 2 bits & $2^{2}$ & 4 & 00 & 01 & 10 & 11 & & & & \\
\hline 3 bits & $2^{3}$ & 8 & 000 & 001 & 010 & 011 & 100 & 101 & 110 & 111 \\
\hline 4 bits & $2^{4}$ & 16 & & & & & & & & \\
\hline 5 bits & $2^{5}$ & 32 & & & & & & & & \\
\hline 6 bits & $2^{6}$ & 64 & & & & & & & & \\
\hline 7 bits & $2^{7}$ & 128 & & & & & & & & \\
\hline 8 bits & $2^{8}$ & 256 & & & & & & & & \\
\hline 16 bits & $2^{16}$ & 65,536 & & & & & & & & \\
\hline 32 bits & $2^{32}$ & $4,294,967,296$ & & & & & & & & \\
\hline
\end{tabular}

3) ASCII is an encoding system used to represent each type character by a number that can be stored in 1 byte. Example: $A$ is 01000001 , $B$ is 01000010 , a is 01100000 and space is 00010000. Determine how many bytes will be required to type in the message:

\section{"An opinion without 3.14 is an onion."}

\section{6 characters $=36$ bytes $=288$ bits}

4) We live in an analog world with all things in nature being continuous variable (always connected and changing) physical quantities. The wind, a swing, music, etc. are all analog systems. Computers and computing systems are digital; therefore, the analog information must be converted to digital information. The best example of this is a typical clock; analog clocks have hands that are in motion constantly while a digital clock only counts (or samples) the time in 1 second increments.

The frequency that sampling occurs is called the sampling rate and is given in samples per second with a unit of Hertz $(\mathrm{Hz})$. The sampling rate of $60 \mathrm{~Hz}$ is 60 samples per second, and the sampling rate of a $55 \mathrm{Kilohertz}(\mathrm{KHz})$ is 55,000 samples per second.

Notice in the figure on the right that the analog sound wave is identical to the original sound wave, however the digital sound wave is stepped. Larger sampling rates, more samples per second, shorten each step and the wave becomes more and more like the original sound wave. If you were to sample your favorite analog song only once every second you would get a much-distorted group of sounds. As the sampling rate is increased the wave distortion decreases, and the sound quality

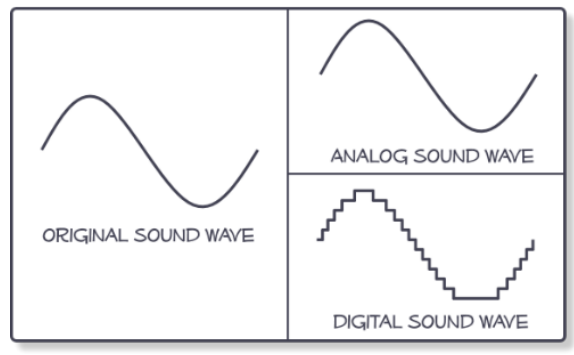
improves. 
Given the following table determine the missing information. The top row is an example.

\begin{tabular}{|c|c|c|c|}
\hline $\begin{array}{c}\text { Period } \\
\text { Sec between samples }\end{array}$ & $\begin{array}{c}\text { Period } \\
\text { Engineering notation }\end{array}$ & $\begin{array}{c}\text { Frequency } \\
\mathrm{Hz} \\
\text { (samples/sec) }\end{array}$ & $\begin{array}{c}\text { Frequency } \\
\text { Engineering Notation }\end{array}$ \\
\hline $0.000133 \mathrm{sec}$ & $133 \mu \mathrm{sec}$ & $7500 \mathrm{~Hz}$ & $7.5 \mathrm{lHz}$ \\
\hline $0.0167 \mathrm{sec}$ & $16.7 \mathrm{msec}$ & $60 \mathrm{~Hz}$ & $6.5 \mathrm{HHz}$ \\
\hline $0.000154 \mathrm{sec}$ & $154 \mu \mathrm{sec}$ & $6,500 \mathrm{~Hz}$ & $12 \mathrm{kHz}$ \\
\hline $0.0000833 \mathrm{sec}$ & $83.3 \mu \mathrm{sec}$ & $12,000 \mathrm{~Hz}$ & $12 \mathrm{mHz}$ \\
\hline $83.3 \mathrm{sec}$ & $83.3 \mathrm{sec}$ & $0.012 \mathrm{~Hz}$ & $920 \mathrm{MHz}$ \\
\hline $0.000000001087 \mathrm{sec}$ & $1.087 \mathrm{nsec}$ & $920,000,000 \mathrm{~Hz}$ & 6 \\
\hline
\end{tabular}

\section{Problem Situation 1.4 Transformers - Fractions and Ratios}

Transformers are electrical components used to increase voltage or decrease voltage. A transformer basically is very simple electro-magnetic passive device that works on the principle of Faraday's law. Mutual induction is the process by which a coil of wire magnetically induces a voltage in a secondary coil located near it. Then we can say that transformers work in the "magnetic domain", and transformers get their name from the fact that they "transform" one voltage and current level into another.

The number of wraps of wire on each side determines how much the voltage is increased or decreased. The primary coil is the one that has the applied voltage and the secondary coil is the coil with the changed voltage.

The primary side is represented with a subscript of $P$ for primary,

- $I_{P}$ is the current on the primary side,

- $V_{P}$ is the voltage on the primary side,

- $\quad \mathrm{N}_{\mathrm{P}}$ is the number of turns of wire on primary coil.

The secondary side is represented with a subscript of $S$ for secondary,

- Is the current on the primary side,

- $\mathrm{V}_{\mathrm{S}}$ is the voltage on the primary side

- $\mathrm{N}_{\mathrm{S}}$ is the number of turns of wire on primary coil.

The turns ratio, $n=\frac{N_{P}}{N_{S}}$ is an important characteristic of a transformer.

The turns ratio may be reduced to a decimal number and is also represented as $N_{P}: N_{S}$.

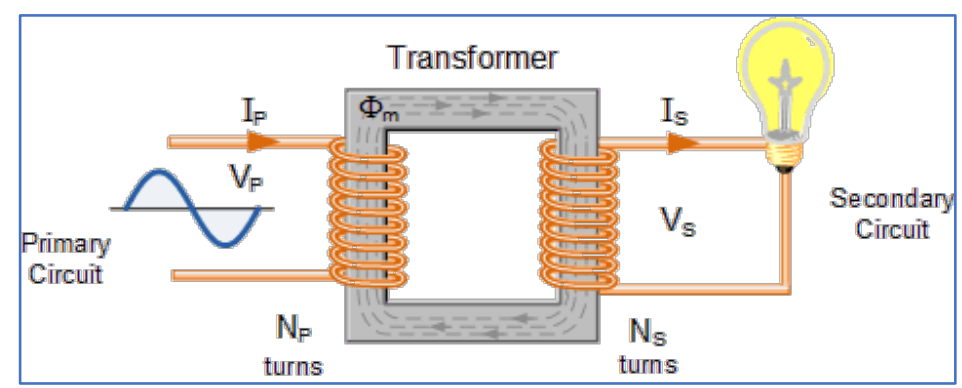


1) A voltage transformer has 2500 turns of wire on its primary coil and 500 turns of wire for its secondary coil. What is the turns ratio $(n)$ of the transformer?

I am asked to determine the turns ratio and I know that $\frac{N_{P}}{N_{S}}=n=\frac{2500 \text { turns }}{500 \text { turns }}=5$

2) Below is a formula that is used to design or analyze any transformer voltage.

$\frac{N_{P}}{N_{S}}=\frac{V_{P}}{V_{S}}$

Given that the input voltage, $V_{P}$ is $120 \mathrm{~V}, N_{P}$ is 3200 and $N_{S}$ is 400 . Determine the secondary voltage, $V_{\mathrm{s}}$.

I am asked to determine the secondary voltage and I know that $\frac{N_{P}}{N_{S}}=\frac{V_{P}}{V_{S}} \rightarrow$ $\frac{3200 \text { turns }}{400 \text { turns }}=\frac{120 \mathrm{~V}}{V_{S}} \rightarrow 8 * V_{S}=120 \mathrm{~V} \rightarrow V_{S}=\frac{120 \mathrm{~V}}{8}=15 \mathrm{~V}$

3) Another method for determining a solution when working with ratios is to cross-multiply the two ratios.

$\frac{N_{P}}{N_{S}}=\frac{V_{P}}{V_{S}} \rightarrow N_{P} V_{S}=V_{P} N_{S}$

Determine the turns on the secondary $\left(N_{S}\right)$ given that $V_{P}=120 \mathrm{~V}, V_{S}=5 \mathrm{~V}$ and $N_{P}=480$ turns.

I need to determine the turns on the secondary of a transformer and I know $N_{P} V_{S}=V_{P} N_{S} \rightarrow$ $\frac{N_{P} V_{S}}{V_{P}}=N_{S}=\frac{480 \text { turns } * 5 \mathrm{~V}}{120 \mathrm{~V}}=20$

Determine the transformer turns ratio $(n)$.

I am asked to determine the turns ratio and I know that $\frac{N_{P}}{N_{S}}=n=\frac{480 \text { turns }}{20 \text { turns }}=24$

This is referred to as a step-down transformer because the voltage is stepped down from the primary side to the secondary side, 120 volts to 5 volts

4) You are to specify a step-up transformer, which is where the secondary voltage is higher than the primary voltage. The primary voltage is 300 Volts, the secondary voltage needs to be 6,000 Volts and the secondary side of the transformer has 12,000 windings. Determine the required turns ratio $(n)$ and the number of windings $\left(N_{P}\right)$ on the primary side.Determine the required turns ratio $(n)$ and the number of windings $\left(\mathrm{N}_{\mathrm{P}}\right)$ on the primary side.

I am asked to determine the turns ratio and the $N_{P}$. Guess is $n$ is $x x x$ and the $N_{P}$ is $x x x$. I know that $\frac{N_{P}}{N_{S}}=\frac{V_{P}}{V_{S}}=n \rightarrow$ So the turns ratio is $\frac{300 \mathrm{~V}}{6000 \mathrm{~V}}=0.05$. I know that $\frac{N_{P}}{N_{S}}=n \rightarrow 0.05=$ $\frac{N_{P}}{12,000 \text { turns }} \rightarrow N_{P}=0.05 * 12,000$ turns $=600$ turns

5) You need to specify a transformer that will run a small heater which requires a secondary voltage, $\mathrm{V}_{\mathrm{S}}=24 \mathrm{~V}$ and a primary voltage, $\mathrm{V}_{\mathrm{P}}=120 \mathrm{~V}$. Determine the turns ratio $(n)$ for this transformer.

I am asked to determine the turns ratio for a step-up transformer. Guess is between $\mathrm{xx}$ and $\mathrm{xx}$. I know that $\frac{V_{P}}{V_{S}}=n \rightarrow$ So the turns ratio is $\frac{120 \mathrm{~V}}{24 \mathrm{~V}}=5$. 